\title{
PERANCANGAN ARSITEKTUR ENTERPRISE MENGGUNAKAN FRAMEWORK TOGAF ADM 9.1 DAN COBIT 4.1
}

\author{
Sofia Umaroh ${ }^{1}$, Nur Fitrianti ${ }^{2}$, Muhammad Iqbal ${ }^{3}$ \\ Sistem Informasi ${ }^{1,2,3}$ \\ Institut Teknologi Nasional \\ Jl. PKH. Mustopha no. 23, Neglasari, Cibeunying \\ Kaler, Kota Bandung, Jawa Barat, 40124 \\ sofia.umaroh@gmail.com ${ }^{1}$, nurfitriani46@gmail.com ${ }^{2}$, hey.iqbal13@gmail.com ${ }^{3}$
}

\begin{abstract}
Abstrak
Penggunaan teknologi informasi menjadi hal yang sangat penting bagi institusi perguruan tinggi untuk mencapai tujuan bisnis serta memberikan fasilitas yang baik pada kegiatan akademik. Sistem yang ada pada perguruan tinggi mempunyai bentuk karakter sistem tersendiri, untuk mengetahui apakah sistem yang ada sudah berjalan sesuai yang di harapkan maka perlu dilakukan pengukuran tingkat kematangannya. Dalam mengintegrasikan sebuah sistem yang baik dibutuhkan sebuah kerangka kerja dalam mengukur tingkat kematangan Teknologi Informasi nya. Pada penelitian ini dilakukan perancangan arsitektur menggunakan kerangka kerja Control Objectives for Information and Related Technology (COBIT) 4.1 dengan domain yang digunakan yaitu $\mathrm{PO} 2$ dan $\mathrm{PO} 3$. Tahapan pertama yang dilakukan pada penelitian ini adalah melakukan pengukuran kematangan Teknologi Informasi menggunakan COBIT 4.1 dengan melakukan penyebaran kuesioner berdasarkan pernyataan pada domain yang digunakan yaitu $\mathrm{PO} 2$ dan $\mathrm{PO}$. Kemudian dilakukan perhitungan nilai dari skala non-existent (level 0) sampai dengan optimised (level 5) serta memiliki gambaran akan kondisi yang diharapkan pada masa yang akan datang. Hasil pengukuran Kematangan Teknologi Informasi pada PO2 diperoleh sebuah nilai yaitu 2,35 yang kondisinya adalah level 2 atau repeatable (pengulangan) dan 2,59 pada $\mathrm{PO} 3$ kondisinya adalah level 3 atau defined (terdefinisi). Berdasarkan kondisi tersebut dapat dijadikan acuan bahwa sistem yang ada di universitas sudah berjalan dengan sesuai harapan namun perlu dilakukan pengembangan secara berkala.
\end{abstract}

Kata kunci:

Arsitektur Enterprise, TOGAF ADM, COBIT 4.1

\begin{abstract}
The use of Information Technology is very important The use of information technology is very important for higher education institutions to achieve
\end{abstract}

business goals and provide good facilities for academic activities. The existing system at the university has its own system character shape, to find out whether the existing system is running as expected, it is necessary to measure the level of maturity. In integrating a good system, a framework is needed to measure the maturity level of Information Technology. In this research, architectural design was carried out using the Control Objectives for Information and Related Technology (COBIT) 4.1 framework with the domain used, namely PO2 and PO3. The first stage carried out in this study was to measure the maturity of Information Technology using COBIT 4.1 by distributing questionnaires based on statements in the domain used, namely $\mathrm{PO} 2$ and $\mathrm{PO}$. Then do the calculation of values from non-existent scale (level 0 ) to optimized (level 5) and have a picture of the expected conditions in the future. The measurement results of Information Technology Maturity at PO2 obtained a value of 2.35 where the condition is level 2 or repeatable and 2.59 at $P O 3$ the condition is level 3 or defined. Based on these conditions, it can be used as a reference that the existing system in university has been running as expected but needs to be developed regularly.

Keywords:

Enterprise Architecture, TOGAF ADM, COBIT 4.1

\section{Pendahuluan}

Teknologi informasi (TI) dan penggunaannya dalam dunia perusahaan, telah mengalami transformasi yang mendasar dalam dekade terakhir. Komponen penting dan menentukan handalnya layanan TI pada sebuah organisasi adalah infrastruktur teknologi informasi yang digunakan, namun untuk memiliki infrastruktur teknologi yang handal, organisasi harus mengeluarkan biaya cukup besar, sehingga banyak organisasi tidak mampu untuk mengadakan infrastruktur TI secara mandiri karena keterbatasan anggaran dan sumber daya(Susanto, 2018). 
Sebuah universitas memiliki elemen yang cukup kompleks, antar elemen selalu bertukar data dan memiliki komunikasi yang cukup kuat, maka dalam mengintegrasikan sebuah teknologi informasinya perlu di bangun suatu arsitektur TI dengan framework sebagai solusi kebutuhan dari permasalahan tiap bagian atau divisi agar terintergasi dan lebih efektif serta efisien(Susanto, 2018).

Kerangka kerja arsitektur enterprise dapat membantu meningkatkan strategi bisnis organisasi, memiliki kemampuan memasarkan inovasi-inovasi terbaru lebih cepat, memiliki informasi dan proses bisnis yang konsisten, lebih aman dan menekan resiko dan biaya penerapan TI. Tujuan kerangka kerja arsitektur enterprise adalah untuk mengoptimalkan proses perubahan strategi bisnis (Sinyal Bandung, 2016). Pendokumentasian elemen-elemen organisasi dapat dilakukan dengan pengembangan arsitektur enterprise. Kerangka kerja arsitektur enterprise yang di gunakan pada penelitian ini adalah TOGAF ADM 9.1, karena kerangka kerja ini memberikan gambaran metode yang detail bagaimana membangun dan mengelola serta mengimplementasikan sistem informasi yang digunakan untuk menggambar sebuah model pengembangan. Arsitektur enterprise yang digunakan hanya sampai pada fase E yaitu Peluang dan Solusi. Sebelum merancang sebuah arsitektur enterprise diperlukan sebuah metode dalam mencari informasi mengenai kodisi arsitektur saat ini, hal yang dilakukan adalah dengan melakukan pengukuran tingkat kematangan TI menggunakan kerangka kerja COBIT 4.1 dengan domain $\mathrm{PO} 2$ dan PO3. Tujuan COBIT 4.1 adalah menyediakan model dasar yang memungkinkan pengembangan aturan yang jelas dan praktek yang baik dalam mengontrol informasi dalam suatu organisasi/perusahaan dalam mencapai tujuannya (Sinyal Bandung, 2016).

Penelitian ini dimaksudkan untuk mengukur kematangan TI serta membangun model arsitektur enterprise dalam mengintegrasikan semua elemen TI yang ada pada universitas untuk mempermudah proses pengembangan arsitektur sistem informasi. Hasil dari penelitian ini berupa nilai kematangan TI berdasarkan PO2 dan PO3 dari COBIT 4.1 dan arsitektur enterprise berdasarkan TOGAF ADM untuk dijadikan blueprint TI guna mendukung aktifitas bisnis di universitas.

Adapun Tujuan dari penelitian ini adalah untuk mengukur tingkat kematangan TI yang ada di universitas dan membangun model Arsitektur Enterprise yang menghasilkan blueprint TI sebagai usulan pengembangan infrastruktur TI dalam mengintegrasikan semua elemen TI yang ada pada kampus universitas

\section{KAJIAN LITERATUR}

\section{II.1. Arsitektur Enterprise}

Arsitektur Enterprise dapat didefinisikan sebagai sebuah blueprint yang menjelaskan bagaimana semua elemen TI dan manajemen bekerja bersama dalam satu kesatuan dan memberikan gambaran eksplisit mengenai hubungan antara proses manajemen dengan TI yang sekarang dan yang diharapkan(Zachman, 1996). Jika dikaitkan dengan enterprise, maka EA harus memebrikan strategi yang memungkinkan organisasi mendukung keadaan yang sekarang dan juga bertindak sebagai roadmap menuju lingkungan yang ditargetkan. Menurut Zachman, Arsitektur perusahaan merupakan sekumpulan representasi yang diperlukan untuk menggambarkan sebuah sistem atau perusahaan berkenaan dengan konstruksi, pemeliharaan, dan perkembangannya (Zachman, 1996). Arsitektur perusahaan merupakan pusat aset informasi strategis yang mendifinisikan misi bisnis, infromasi yang diperlukan untuk menjalankan misi, teknologi yang diperlukan untuk menjalankan misi, dan proses-proses tradisional untuk mengimplementasikan teknologi baru sebagai respon terhadap perubahan kebutuhankebutuhan misi (Zachman, 1996).

\section{II.2. Kerangka Kerja Arsitektur Enterprise}

Kerangka kerja arsitektur enterprise yang akan diukur terdiri dari empat yaitu Zachman, TOGAF, FEA, dan Gartner. Rating yang berikan antara satu sampai dengan empat (very poor-poor-acceptablevery good) seperti pada tabel 1 berikut (Mrdalj, 2016).

Tabel 1 Criteria and Rating for EA Framework(Mrdalj, 2016)

\begin{tabular}{|l|c|c|c|c|}
\hline & \multicolumn{4}{|c|}{ Ratings } \\
\hline Criteria & Zachman & TOGAF & FEA & Gartner \\
\hline Taxonomy Completeness & 4 & 2 & 2 & 1 \\
\hline Process Completeness & 1 & 4 & 2 & 3 \\
\hline Reference Model Guidance & 1 & 3 & 4 & 1 \\
\hline Practice Guidance & 1 & 2 & 2 & 4 \\
\hline Maturity Model & 1 & 1 & 3 & 2 \\
\hline Business Focus & 1 & 2 & 1 & 4 \\
\hline Governance Guidance & 1 & 2 & 3 & 3 \\
\hline Partitioning Guidance & 1 & 2 & 4 & 3 \\
\hline Prescriptive Catalog & 1 & 2 & 4 & 2 \\
\hline Vendor Neutrality & 2 & 4 & 3 & 1 \\
\hline Information Availability & 2 & 4 & 2 & 1 \\
\hline Time to Value & 1 & 3 & 1 & 4 \\
\hline
\end{tabular}

Berdasarkan tabel 1 dapat dilihat bahwa masingmasing dari framework memiliki kelemahan dan kekuatan. Beberapa kerangka kerja enterprise arsitektur yang dibandingkan dalam penelitian ini adalah Zachman, DoDAF, FEAF, TEAF, dan TOGAF. Hasil dari kajian terlihat dalam tabel 2 berikut (Mrdalj, 2016). 
Tabel 2 Comparison by Views/ Perspectives(Mrdalj, 2016)

\begin{tabular}{|c|c|c|c|c|c|c|}
\hline Framework & Planner & Owner & Designer & Builder & Subcontractor & $\mathbf{U}$ \\
\hline Zachman & Scope & $\begin{array}{c}\text { Business } \\
\text { Model }\end{array}$ & $\begin{array}{l}\text { System } \\
\text { Model }\end{array}$ & $\begin{array}{c}\text { Technology } \\
\text { Model }\end{array}$ & $\begin{array}{c}\text { Detailed } \\
\text { Representations }\end{array}$ & $\begin{array}{l}\text { Funct } \\
\text { Sy }\end{array}$ \\
\hline DoDAF & All View & $\begin{array}{c}\text { Operational } \\
\text { View }\end{array}$ & $\begin{array}{l}\text { Systems } \\
\text { View }\end{array}$ & $\begin{array}{c}\text { Technical } \\
\text { View }\end{array}$ & & \\
\hline FEAF & $\begin{array}{l}\text { Objectives/Scope } \\
\text { Planner's View }\end{array}$ & $\begin{array}{l}\text { Enterprise } \\
\text { Model } \\
\text { Owner's } \\
\text { View }\end{array}$ & $\begin{array}{l}\text { Information } \\
\text { Systems } \\
\text { Model } \\
\text { Designer's } \\
\text { View }\end{array}$ & $\begin{array}{c}\text { Technology } \\
\text { Model } \\
\text { Builder's } \\
\text { View }\end{array}$ & $\begin{array}{c}\text { Detailed } \\
\text { Specifications } \\
\text { Subcontractor's } \\
\text { View }\end{array}$ & \\
\hline TEAF & Planner & Owner & Designer & \multicolumn{2}{|c|}{ Builder } & \\
\hline TOGAF & & $\begin{array}{c}\text { Business } \\
\text { Architecture } \\
\text { View }\end{array}$ & \multicolumn{2}{|c|}{$\begin{array}{l}\text { Technical Anchitecture } \\
\text { Views }\end{array}$} & & \\
\hline
\end{tabular}

Berdasarkan tabel 2 dapat dilihat bahwa TOGAF kuat dalam aspek arsitektur bisnis dan Arsitektur teknis dan hanya fokus pada perencanaan arsitektur tidak memberikan detail sebanyak dari aspek perencanaan dan pemeliharaan. TOGAF adalah salah satu yang paling komprehensif sehubungan dengan proses aktual yang terlibat. Kerangka kerja ini menyediakan pedoman menuju prinsip-prinsip untuk pengambilan keputusan, pedoman sumber daya TI, dan prinsipprinsip arsitektur(Mrdalj, 2016). Perbandingan dalam segi abstraksi dapat dilihat pada tabel 3.

Tabel 3 Comparison by Abstractions(Mrdalj, 2016)

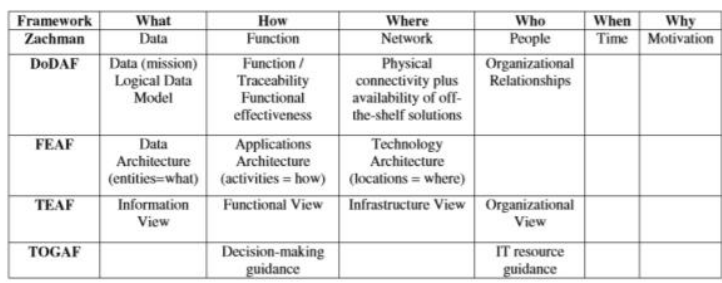

Berdasarkan tabel 3 dapat dilihat bahwa TOGAF memberikan panduan dalam menentukan bagaimana strategis TI dapat dikembangkan dengan lebih terstruktur(Mrdalj, 2016). Perbandingan dengan fase SDLC dapat dilihat pada tabel 4.

Tabel 4 Comparison by SDLC Phases(Mrdalj, 2016)

\begin{tabular}{|c|c|c|c|c|c|}
\hline $\begin{array}{l}\text { SDLC Phase/ } \\
\text { Framework }\end{array}$ & Planning & Analysis & Design & Implementation & Maintenane \\
\hline Zachman & Yes & Yes & Yes & Yes & No \\
\hline DoDAF & Yes & Yes & Yes & Describes final products & No \\
\hline FEAF & Yes & Yes & Yes & Yes & $\begin{array}{l}\text { Detailed } \\
\text { Subcontractor's' }\end{array}$ \\
\hline TEAF & Yes & $\begin{array}{l}\text { Owner's } \\
\text { Analysis }\end{array}$ & Yes & Yes & No \\
\hline TOGAF & & $\begin{array}{l}\text { principles tha } \\
\text { provide guid } \\
\text { principles for }\end{array}$ & $\begin{array}{l}\text { pport de } \\
\text { ig of IT } \\
\text { ign and }\end{array}$ & $\begin{array}{l}\text { n making across enterprise; } \\
\text { urres; support architecture } \\
\text { mentation }\end{array}$ & \\
\hline
\end{tabular}

Berdasarkan tabel 4 dapat dilihat bahawa secara keseluruhan, kerangka kerja dapat menentukan bagaimana sistem akan dikembangkan sebagai alat kerja, dan secara umum hal ini diukur berdasarkan perencanaan dan analisis. Pada kerangka kerja dalam siklus pengembangan sistem dapat dilihat bahwa TOGAF mengacu pada prinsip arsitektur untuk perancangan dan penerapannya.

Dari semua perbandingan yang sudah di jelaskan pada tabel 1, 2,.3, dan 4 dapat disimpulkan bahwa kerangka kerja yang di ambil pada penelitian ini dalam perancangan sebuah arsitektur enterpise yang paling relevan adalah kerangka kerja TOGAF.

\section{II.3. The Open Group Architecture Framework (TOGAF)}

Berikut ini adalah struktur dan komponen dari TOGAF Architecture Development Method yang menjelaskan bagaimana menemukan sebuah arsitektur perusahaan/organisasi secara khusus berdasarkan kebutuhan bisnisnya. Ini merupakan bagian utama dari TOGAF. Bentuk struktur dari TOGAF-ADM adalah seperti pada Gambar 2.1 berikut ini.

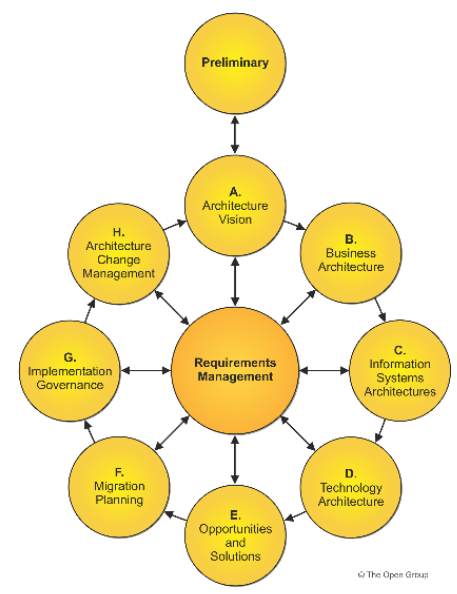

Gambar 1. TOGAF Architecture Development Method(Standard \& Group, 2011)

ADM meliputi 9 tahapan dasar, tetapi dalam penelitian ini hanya akan dianalisa 6 tahapan dari 9 tahapan diatas yaitu tahapan persiapan, architecture vision, business architecture, information system architecture, technology architecture, dan Opportunities and Solutions yaitu (Standard \& Group, 2011):

a. Tahap persiapan (Preliminary Phase): Mendefinisikan kerangka dan prinsip.

b. Phase A: Architecture Vision. Mendefinisikan scope, vision dan memetakan strategi.

c. Phase B: Business Architecture. Mendeskripsikan bisnis arsitektur saat ini dan sasaran dan menentukan celah (gap) di antara mereka.

d. Phase C: Information System Architecture. Mengembangkan arsitektur sasaran untuk data dan aplikasi.

e. Phase D: Technology Architecture. Menciptakan sasaran keseluruhan arsitektur yang akan diterapkan pada tahapan kedepan.

f. Phase E: Opportunities and Solutions. Mengembangkan strategi keseluruhan, menentukan apa yang akan dibeli, membangun 
atau penggunaan ulang, dan bagaimana menerapkan arsitektur yang dideskripsikan di phase D

\section{II.4. COBIT Framework (Control Objectives for Information and Related Technology)}

COBIT adalah suatu metodologi yang memberikan kerangka dasar dalam menciptakan sebuah TI yang sesuai dengan kebutuhan organisasi (IT Governance Institute, 2007). Tujuan COBIT adalah menyediakan model dasar yang memungkinkan pengembangan atura yang jelas dan praktek yang baik dalam mengontrol informasi dalam suatu organisasi/perusahaan dalam mencapai tujuannya. COBIT adalah suatu framework untuk membangun suatu IT Governance. Dalam penelitian ini hanya akan dianalisa pada domain Planning and Organization (PO) pada proses PO2 (Pendefinisian arsitektur informasi) dan PO3 (Penyelarasan teknologi).

\section{II.5. Model Kematangan TI}

Model Kematangan (Maturity Model) digunakan sebagai alat untuk melakukan bencmarking dan selfassessment oleh manajemen teknologi informasisecara lebih efisien. Model kematangan untuk pengelolaan dan kontrol pada proses teknologi informasi didasarkan pada metode evaluasi perusahaan atau organisasi, sehingga dapat mengevaluasi sendiri, mulai dari level 0 (non-exixtent) hingga level 5 (Optimised) (IT Governance Institute, 2007). Tabel 5 merupakan penjelasan mengenai kriteria kematangan TI.

Tabel 5. Model kematangan TI(IT Governance Institute, 2007)

\begin{tabular}{cc}
\hline \hline Bobot & Keterangan \\
\hline \hline $\begin{array}{c}\text { Existent) } \\
\text { (Non }\end{array}$ & $\begin{array}{c}\text { Tidak ada proses yang dapat dikenali. } \\
\text { masalah yang harus diatasi. }\end{array}$ \\
\hline \hline 1 & $\begin{array}{c}\text { Ada buktu bahwa perusahaan telah } \\
\text { mengakui bahwa masalah ada dan perlu }\end{array}$ \\
\hline \hline
\end{tabular}

\begin{tabular}{|c|c|}
\hline (initial) & $\begin{array}{l}\text { ditangani. Namun, tidak ada proses standar; } \\
\text { sebaliknya, ada pendekatan adhoc yang } \\
\text { cenderung diterapkan pada individu atau kasus } \\
\text { per kasus. Pendekatan keseluruhan untuk } \\
\text { manajemen tidak terorganisir }\end{array}$ \\
\hline $\begin{array}{c}2 \\
\text { (Repeatable) }\end{array}$ & $\begin{array}{l}\text { Proses telah berkembang ke tahap di mana } \\
\text { prosedur serupa diikuti oleh orang yang berbeda } \\
\text { melakukan tugas yang sama. Tidak ada pelatihan } \\
\text { formal atau komunikasi prosedur standar, dan } \\
\text { tanggung jawab diserahkan kepada individu } \\
\text { tersebut. Ada tingkat ketergantungan yang tinggi } \\
\text { pada pengetahuan individu dan, oleh karena itu, } \\
\text { kesalahan mungkin terjadi }\end{array}$ \\
\hline $\begin{array}{c}3 \\
\text { (Defined) }\end{array}$ & $\begin{array}{l}\text { Prosedur telah di standarisasi dan } \\
\text { didokumentasikan, dan dikomunikasikan } \\
\text { melalui pelatihan. Diamanatkan bahwa proses ini } \\
\text { harus diikuti; namun, kecil kemungkinan } \\
\text { penyimpangan akan terdeteksi. Prosedurnya } \\
\text { sendiri tidak canggih tetapi merupakan } \\
\text { formalisasi dari praktik yang ada }\end{array}$ \\
\hline $\begin{array}{c}4 \\
\text { (Managed) }\end{array}$ & $\begin{array}{l}\text { Manajemen memantau dan mengukur } \\
\text { kepatuhan terhadap prosedur dan mengambil } \\
\text { tindakan di mana proses tampaknya tidak } \\
\text { berfungsi secara efektif. Proses sedang dalam } \\
\text { perbaikan konstan dan memberikan praktik yang } \\
\text { baik. Otomasi dan alat digunakan secara terbatas } \\
\text { atau terfragmentasi. }\end{array}$ \\
\hline $\begin{array}{c}5 \\
(\text { Optimised })\end{array}$ & $\begin{array}{l}\text { Proses telah disempurnakan ke tingkat } \\
\text { praktik yang baik, berdasarkan hasil peningkatan } \\
\text { berkelanjutan dan pemodelan kematangan } \\
\text { dengan perusahaan lain. TI digunakan secara } \\
\text { terpadu untuk mengotomatisasi alur kerja, } \\
\text { menyediakan alat untuk meningkatkan kualitas } \\
\text { dan efektivitas, membuat perusahaan cepat } \\
\text { beradaptasi. }\end{array}$ \\
\hline
\end{tabular}

Pada penelitian ini, desain penelitian merujuk pada Kerangka dalam Information System Research Framework, Hevner (Hevner, March, Park, \& Ram, 2004). Dengan penjelasan setiap bagiannya seperti pada Gambar 2 


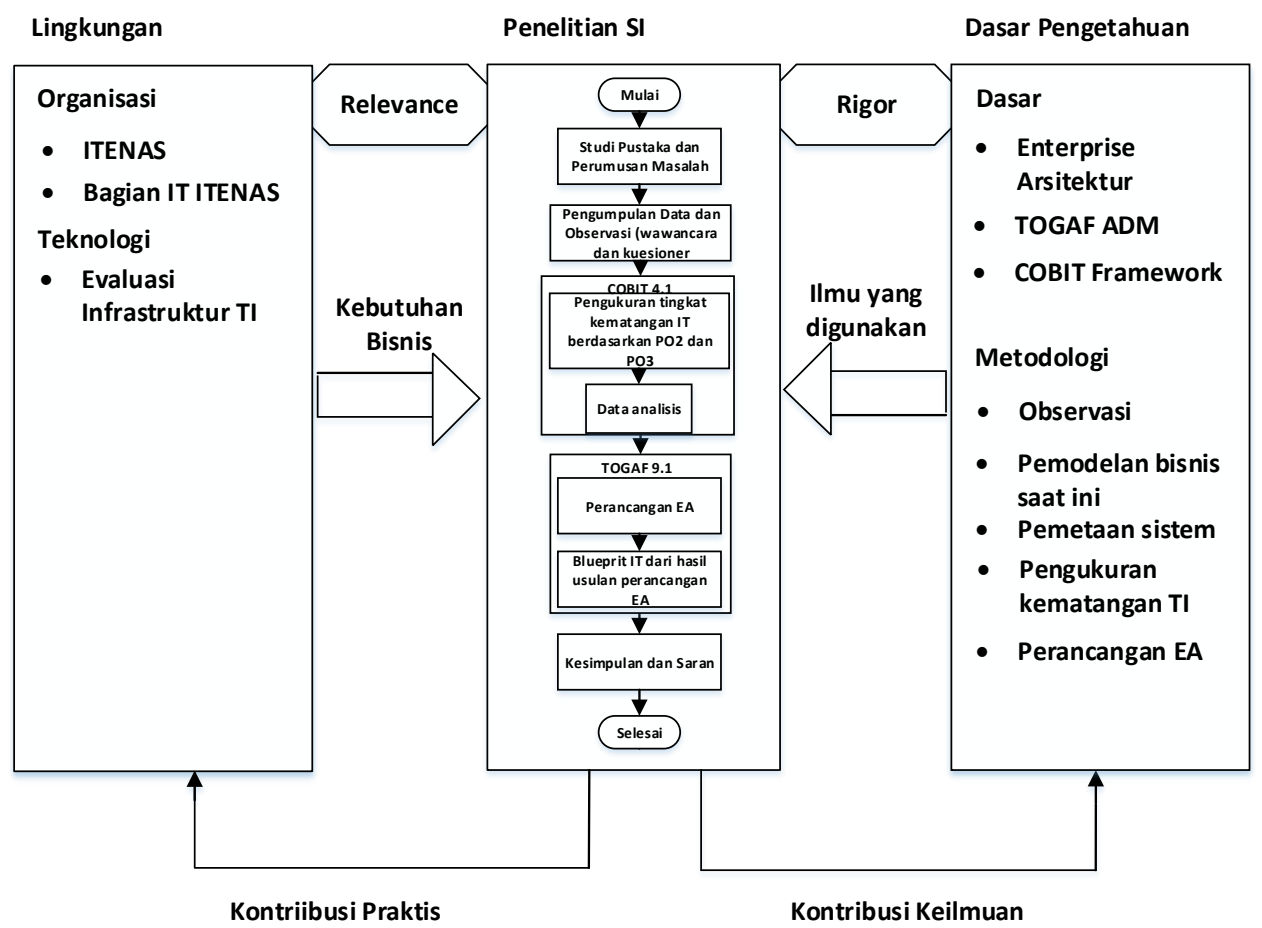

Gambar 2 Metodologi Penelitian Hevner

\section{A. Lingkungan}

\section{Organisasi}

Bagian ini menunjukkan pihak mana saja yang terlibat dalam penelitian ini. Dalam penelitian ini yang membangun model Architecture Enterprise pada semua elemen TI yang ada pada universitas untuk mempermudah proses pengembangan arsitektur sistem informasi, pihak yang terlibat merupakan universitas sebagai organisasi yang akan di analisis penerapan TI nya, dan bagian TI sebagai sumber informasi mengenai penerapan TI di universitas.

\section{Teknologi}

Bagian ini menunjukkan teknologi apa saja yang digunakan dalam penelitian, dalam hal ini teknologi apa saja yang digunakan untuk membangun sebuah Arsitektur Enterprise, yaitu infrastruktur TI yang ada pada universitas seperti yang sudah dijelaskan pada latar belakang.

\section{B. Penelitian Sistem Informasi}

Bagian ini menjelaskan mengenai detail tahapan penelitian sistem informasi yang dilakukan dalam penelitian seperti pada Gambar 2. Proses ini di awali dengan pencarian studi pustaka dan perumusan masalah, kemudian melakukan pengumpulan data dan observasi menggunakan kuesioner dan wawancara pada divisi IT universitas, hal ini digunakan untuk melakukan pengukuran tingkat kematangan TI menggunakan kerangka kerja COBIT berdasarkan PO2 dan PO3 kemudian data di analisis. Perancangan enterprise arsitektur dilakukan dengan menggunakan kerangka kerja TOGAF berdasarkan hasil dari kerangka kerja COBIT pada domain PO2 dan PO3 juga. Dari hasil enterprise arsitektur tersebut akan dijadikan rekomendasi blueprint TI untuk universitas

\section{Dasar Pengetahuan}

\section{Pengetahuan}

Pengetahuan yang dijadikan sebagai landasan teori yaitu enterprise arsitektur, kerangka kerja COBIT dan kerangka TOGAF seperti yang sudah di jelaskan pada bab 2.

\section{Metodologi}

Metodologi yang digunakan pada penelitian ini adalah melakukan observasi dengan melakukan wawancara dan pengisian kuesioner pada divisi IT di universitas. Kemudian melakukan pengukuran kematangan TI dengan menggunakan kerangka kerja COBIT. Dari hasil pengukuran kematangan TI di lakukan pemetaan sistem dan pemodelan bisnis saat ini dengan menggunakan kerangka kerja TOGAF sebagai usulan perancangan enterprise arsitektur. 


\section{III.ANALISIS DAN PERANCANGAN}

\section{Pengukuran Tingkat Kematangan Menggunakan COBIT 4.1}

Dari pelaksanaan survey kuesioer maturity level, diperoleh jawaban atas kuesioner tersebut sebanyak jumlah kuesioner yang telah di distribusikan kepada para responden yang teridentifikasi 6 orang. Dari hasil jawaban reponden dapat dibuat suatu rekapitulasi seperti pada tabel 6 berikut ini :

Tabel 6. Tingkat Kematangan TI

\begin{tabular}{|c|c|c|c|c|c|}
\hline \multirow[b]{2}{*}{ No } & \multirow{2}{*}{\multicolumn{2}{|c|}{ Domain proses TI }} & \multicolumn{3}{|c|}{ Tingkat kematangan } \\
\hline & & & $\begin{array}{l}\text { Saat } \\
\text { ini }\end{array}$ & Harapan & $\begin{array}{l}\text { Kesenjangan } \\
\text { (gap) }\end{array}$ \\
\hline 1 & $\mathrm{PO} 2$ & $\begin{array}{l}\text { Menentukan } \\
\text { arsitektur } \\
\text { informasi }\end{array}$ & 2,35 & 3,00 & 0,65 \\
\hline 2 & PO3 & $\begin{array}{l}\text { Menentukan } \\
\text { arah } \\
\text { teknologi }\end{array}$ & 2,59 & 3,00 & 0,41 \\
\hline \multicolumn{3}{|c|}{ Jumlah } & 4,94 & 6,00 & 1,06 \\
\hline \multicolumn{3}{|c|}{ Rata-rata } & 2,47 & 3,00 & 0,53 \\
\hline
\end{tabular}

Berdasarkan rata-rata nilai tingkat kematangan TI pada universitas pada tabel 6 , dapat digambarkan tingkat kematangannya pada gambar 3 sebagai berikut :

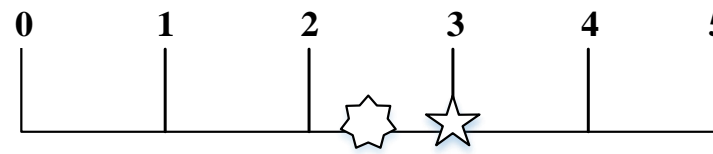

Gambar 3. Tingkat kematangan TI

Arti Simbol :

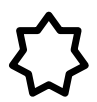

Status organisasi pada saat ini

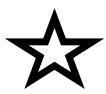

Status organisasi yang diharapkan

Secara umum dari hasil rekapitulasi kuesioner maturity level pada tabel 4.1 diperoleh kecenderungan fakta dilapangan tentang tingkat kematangan proses perencanaan strategis TI baik saat ini maupun yang diharapkan. Pembahasan dan rekomendasi dari hasil evaluasi mengenai tingkat kematangan adalah sebagai berikut.

a. Hasil Evaluasi PO2
Nilai akhir dari hasil tingkat kematangan adalah 2,35 jika ditinjau berdasarkan nilai level tingkat kematangan pada tabel 5 maka nilai tersebut kondisinya adalah level 2 atau repeatable (pengulangan). Kondisi tersebut menjelaskan bahwa organisasi sudah mengetahui bahkan sudah melakukan pengembangan dalam proses - proses untuk menerapkan arsitektur, dan diikuti oleh setiap orang yang telibat didalamnya. Kondisi ini belum ideal untuk mencapai target yang diharapkan yaitu level 3 atau Terdefinisi (Defined). Berdasarkan hasil evaluai pada domain PO2 maka rekomendasi yang diberikan adalah melakukan sebuah perancangan arsitektur enterprise dengan mengacu pada framework TOGAF ADM 9.1 agar dapat mencapai target tingkat kematangan yang di harapkan karena sudah di standarisasi. Kondisi ini akan dijadikan referensi dalam perancangan enterprise pada tahap mendefinisikan visi arsitektur yang akan menghasilkan prinsip-prinsip arsitektur yang ideal bagi perusahaan.

\section{b. Hasil Evaluasi PO3}

Nilai akhir dari hasil tingkat kematangan adalah 2,59 jika ditinjau berdasarkan nilai level tingkat kematangan pada tabel 3.4 maka nilai tersebut kondisinya adalah level 3 atau defined (terdefinisi). Kondisi tersebut sesuai dengan target yang diharapkan karena menjelaskan bahwa prosedur dalam menentukan infrastruktur teknologi informasi di universitas telah distandarisasi, didokumentasikan, dan dikomunikasikan melalui pelatihan. sudah ada dokumentasi dan kebijakan dari teknologi yang 5 digunakan. Prosedur tentang instalasi dan infrastruktur sudah ada. Arah dan pengembangan teknologi sudah terdokumentasi di blueprint IT universitas. Sudah terdokumentasi untuk kondisi saat ini dan individu yang membuat pengembangan teknologi informasi juga sudah ada.

Berdasarkan kondisi saat ini maka untuk meningkatkan perusahaan dalam mengembangkan sebuah infrastruktur teknologi yaitu dengan cara melakukan perancangan arsitektur teknologi tujuannya adalah agar teknologi informasi yang diterapkan di universitas dapat terdokumentasi lebih detail mengenai pengembangan infrastruktur teknologinya serta dapat mengintegrasikan teknologi dengan sistem informasi yang ada, proses ini juga mengacu pada framework TOGAF ADM 9.1 pada fase mendefinisikan teknologi. Dengan adanya arsitektur teknologi maka perusahaan memilliki standar mengenai teknologi apa saja yang sudah dan akan diterapkan dan membantu dalam pengembangan infrastruktur teknologi. Kondisi ini akan dijadikan referensi dalam perancangan arsitektur enterprise pada tahap mendefinisikan target arsitektur teknologi yang akan menghasilkan solusi dari isu infrastruktur teknologi yang sesuai bagi perusahaan.. 


\section{Perancangan Arsitektur Enterprise Menggunakan TOGAF ADM 9.1}

Fase Preliminary

Berdasarkan tinjauan dari hasil wawancara dan hasil evaluasi tingkat kematangan domain PO2 dan PO3 yang dilakukan di universitas dapat disimpulkan bahwa universitas ini berpotensi dapat menerapkan prinsip arsitektur sebagai berikut. maka gambaran umum mengenai prinsip arsitektur yang ada di universitas yang dapat dijadikan rekomendasi dapat dilihat pada tabel 7.

Tabel 7 Prinsip Arsitektur

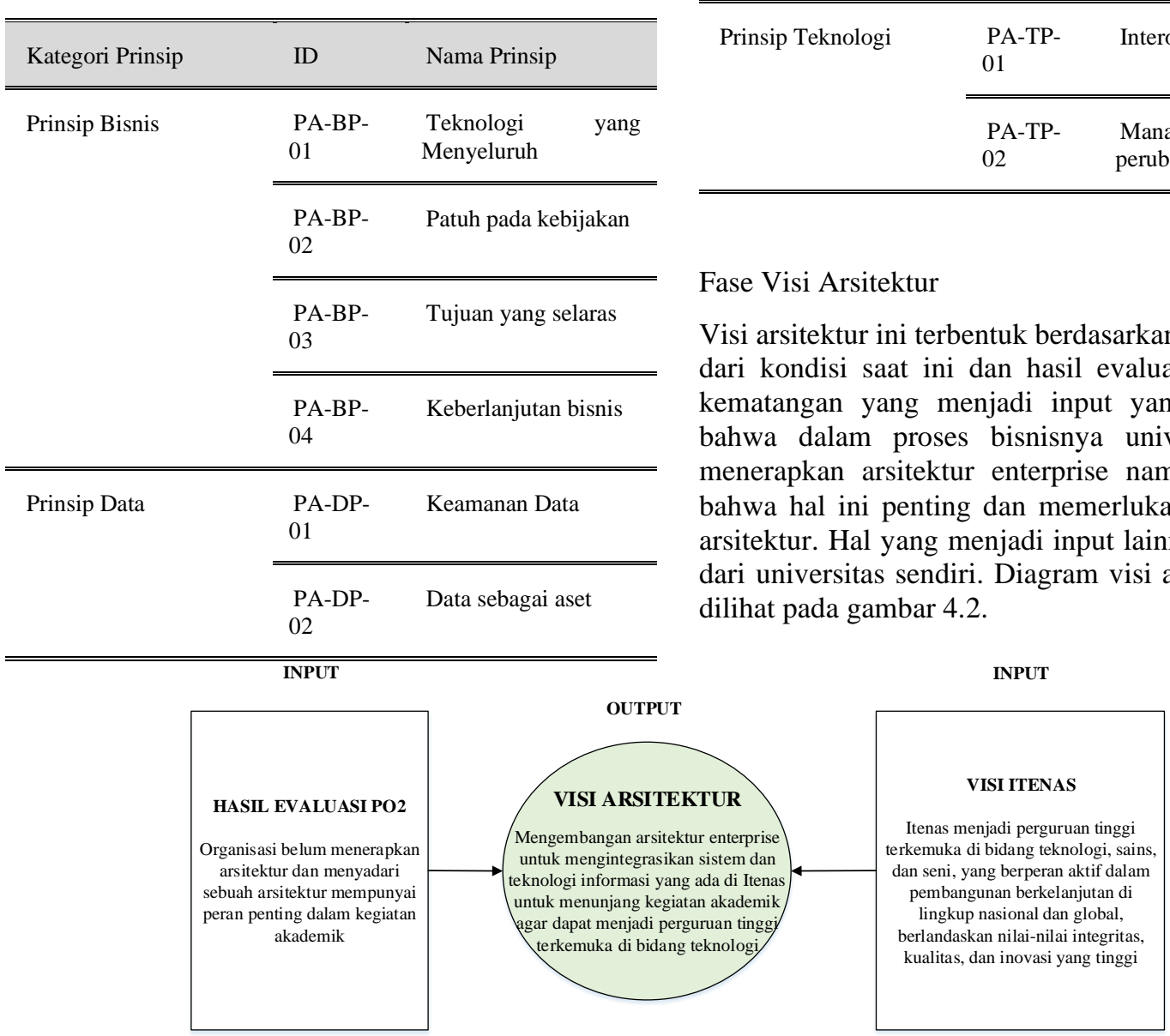

\section{Gambar 4 Visi Arsitektur}

\section{Fase Arsitektur Bisnis}

Perbedaan utama dari proses bisnis target dan proses bisnis saat ini terletak pada penambahan proses bisnis utama yaitu penunjang tugas akhir pada proses Kemahasiswaan dan Pengelolaan Nilai pada proses Akademik. Berdasarkan analisis mengenai kondisi awal menunjukkan bahwa proses ini sudah ada namun hanya digunakan pada salah satu jurusan di universitas. Agar semua jurusan yang ada di universitas dapat menerapkan proses tersebut maka proses ini perlu

\begin{tabular}{|c|c|c|}
\hline & $\begin{array}{l}\text { PA-DP- } \\
03\end{array}$ & Data dapat di akses \\
\hline & $\begin{array}{l}\text { PA-DP- } \\
04\end{array}$ & Pengawasasan data \\
\hline \multirow[t]{3}{*}{ Prinsip Aplikasi } & $\begin{array}{l}\text { PA-AP- } \\
01\end{array}$ & $\begin{array}{l}\text { Kemandirian } \\
\text { teknologi }\end{array}$ \\
\hline & $\begin{array}{l}\text { PA-AP- } \\
02\end{array}$ & $\begin{array}{c}\text { Kemudahan dalam } \\
\text { penggunaan }\end{array}$ \\
\hline & $\begin{array}{l}\text { PA-AP- } \\
03\end{array}$ & Aplikasi reliable \\
\hline \multirow[t]{2}{*}{ Prinsip Teknologi } & $\begin{array}{l}\text { PA-TP- } \\
01\end{array}$ & Interopabilitas \\
\hline & $\begin{array}{l}\text { PA-TP- } \\
02\end{array}$ & $\begin{array}{l}\text { Manajemen } \\
\text { perubahan responsif }\end{array}$ \\
\hline
\end{tabular}

\section{Fase Visi Arsitektur}

Visi arsitektur ini terbentuk berdasarkan pertimbangan

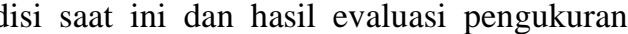
anersitas belum menerapkan arsitektur enterprise namun menyadari erlukan perancangan universitas sendiri. Diagram visi arsitektur dapat INPUT 
siswa kelas akhir yang akan mendaftar ke perguruan tinggi dan diharapkan dapat menjadi calon mahasiswa yang mendaftar ke universitas. Penerapan metode sosialisasi dilakukan kepada biro promosi dan mahasiswa yang ikut serta dalam melakukan sosialisasi kepada calon mahasiswa. Dengan adanya proses ini diharapkan bertambahnya calon mahasiswa yang mendaftar ke universitas ini. Gambar 5 menunjukan valuechain diagram proses bisnis target pada universitas. Perubahan hanya menambahkan proses penunjang tugas akhir dan proses promosi

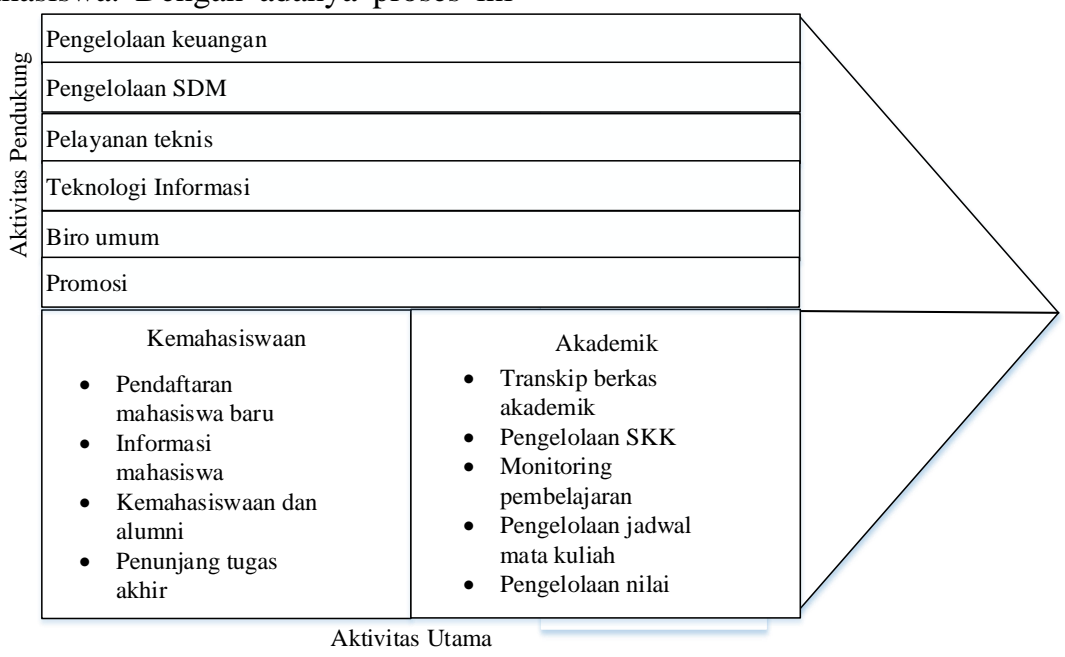

Gambar 5 Valuechain proses bisnis target

a. Aktivitas Utama

- Kemahasiswaan

Aktivitas yang mendukung kegiatan perkuliahan mahasiswa yang meliputi proses penerimaan mahasiswa baru hingga penerimaan mahasiswa, informasi mahasiswa seperti data absen dan nilai, informasi kemahasiswaan dan beasiswa, dan proses penunjang tugas akhir mahasiswa.

\section{- Akademik}

Ativitas proses administrasi akademik yang berhubungan dengan pengelolaan berkas akademik seperti KRS dll, pengelolaan Sistem Kredit Kemahasiswaan (ko-kurikuler, ekstra-kurikuler dan kegiatan kemasyarakatan, penjadwalan mata kuliah, dan pengelolaan nilai.

b. Aktivitas Pendukung

- Pengelolaan Keuangan

Aktivitas yang berkaitan dengan usaha untuk memberikan dukungan manajemen keuangan yang berkisar mulai dari perencanaan, eksekusi, pelaporan, sampai audit.

\section{- Pengelolaan SDM}

Aktivitas pendukung untuk penentuan kebutuhan, pemantauan dan alokasi sumber daya manusia khususnya pada aktivitas operasional akademik mulai dari pendataan, penilaian kinerja, sampai kenaikan jabatan akademik.

- Pelaksana teknis

Aktivitas pengelolaan teknis untuk mendukung kegiatan pendidikan, termasuk juga didalamnya pengelolaan perpustakaan dan laboratorium.

\section{- Biro Umum}

Aktivitas pengelolaan sarana dan prasarana pendukung universitas, meliputi penyediaan ruang, manajemen asset, perelengkapan perkuliahan serta proses akademik dan pengelolaan rapat sebagai usulan.

- Teknologi Informasi

Aktivitas pengelolaan teknologi informasi yang mencakup fungsi bisnis riset \& pengembangan teknologi, pemeliharaan jaringan, dan pemeliharaan sistem informasi.

- Promosi

Aktivitas mengenai proses pelaksanaan promosi yang menggunakan metode sosialisasi kepada beberapa sekolah dengan tujuan siswa kelas akhir dapat mendaftar sebagai mahasiswa di universitas.

\section{Fase Arsitektur data}

Target arsitektur data dapat dipetakan dengan memahami gambaran target arsitektur data dan target hubungan antara arsitektur data dan arsitektur bisnis. Entitas data pada target arsitektur data di universitas 
tidak mengalami banyak perubahan. Namun terdapat penambahan entitas-entitas data baru dikarenakan adanya penambahan-penambahan proses bisnis penunjang tugas akhir dan promosi serta fungsi bisnis manajemen rapat. Gambaran target struktur data dapat dilihat pada gambar 6

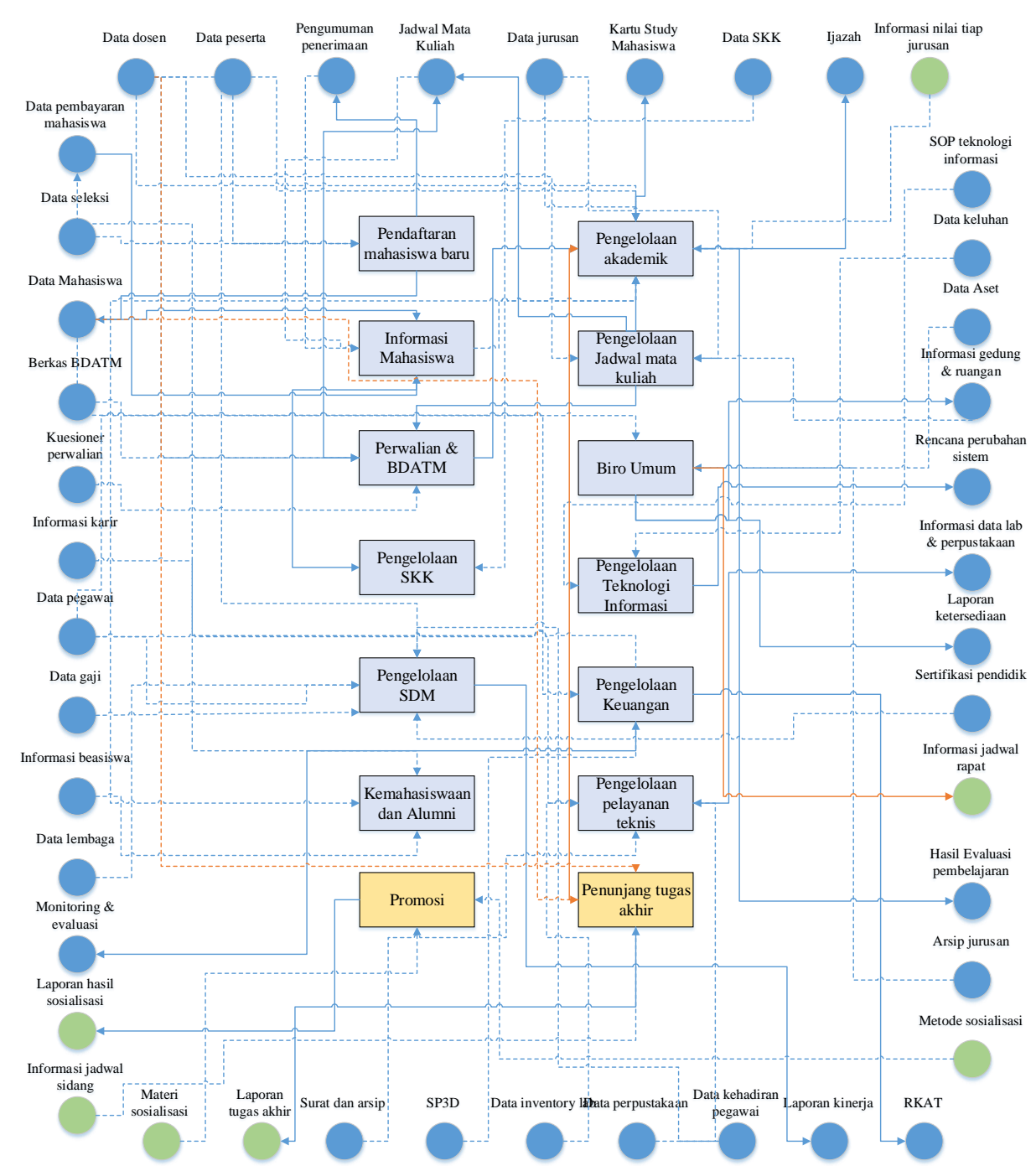

Gambar 6 Target hubungan arsitektur data dan arsitektur bisnis
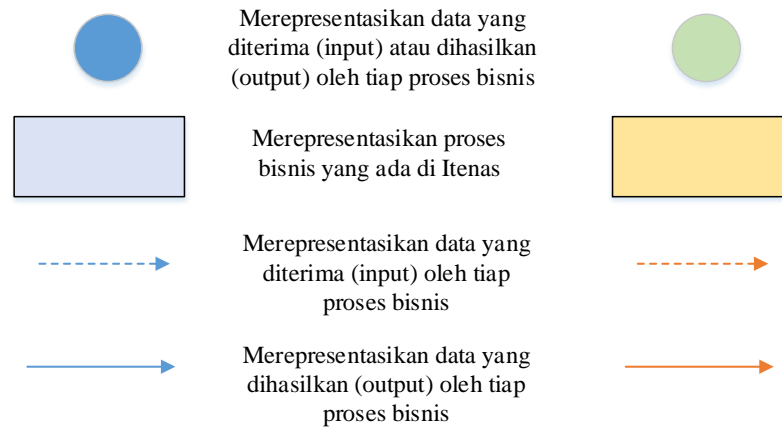

Merepresentasikan data yang ditambahkan di target arsitektur data

Merepresentasikan target proses bisnis yang ditambahkan

Merepresentasikan data yang diterima (input) oleh target proses bisnis

Merepresentasikan data yang dihasilkan (output) oleh target proses bisnis

Gambar 7 Petunjuk diagram hubungan arsitektur data dan arsitektur bisnis 
Fase Arsitektur Aplikasi

Target Arsitektur aplikasi adalah adanya integrasi pada aplikasi Sistem Nilai dan SITA (Sistem Informasi Tugas Akhir), karna berdasarkan analisis hubungan antar aplikasi dan arsitektur data awal kedua aplikasi ini sudah ada namun sumber data yang di akses bersifat masing-masing dan belum terhubung dengan database pusat. Sementara analisis juga dilakukan dengan menambahkan aplikasi baru yang terintegrasi seperti SISPROM (Sistem Informasi Promosi) dan SISPAT (Sistem Informasi Rapat) guna menjawab penjelasan kebutuhan proses bisnis di universitas yang sudah dijelaskan pada subbab target proses bisnis. Gambaran integrasi seluruh aplikasi dapat dilihat pada gambar 8 Diagram biru menunjukan aplikasi yang baru terintegrasi.

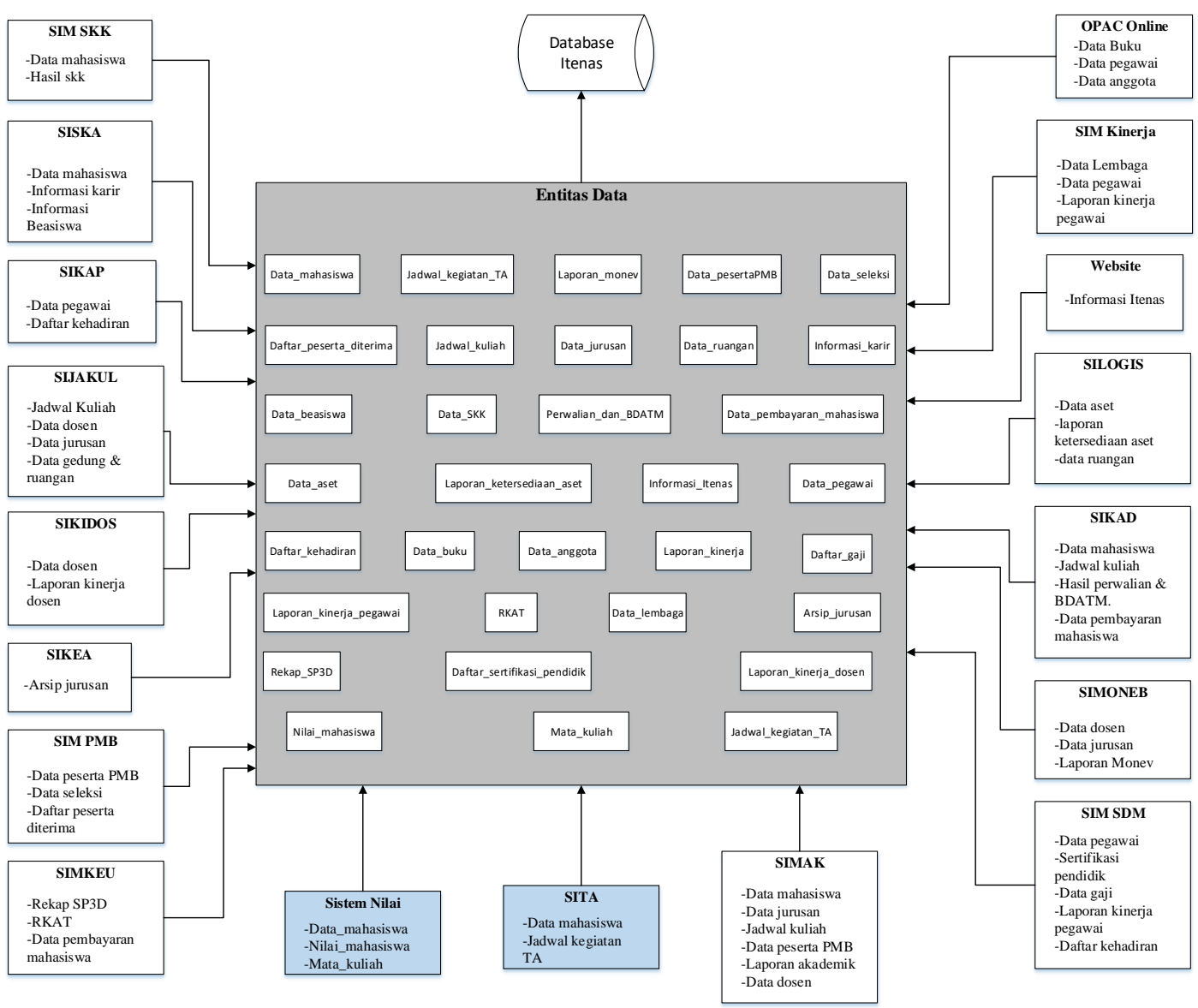

Gambar 8 Arsitektur Aplikasi

Fase Arsitektur Teknologi

Pembahasan mengenai arsitektur teknologi awal dapat dilaksanakan dengan memetakan kondisi arsitektur teknologi saat ini ke komponen-komponen dan infrastruktur yang ada beserta memahami hubungan arsitektur teknologi dengan layer aplikasi. Dalam melakukan analisis mengenai arsitektur teknologi hal yang perlu dilakukan adalah dengan menjelaskan kondisi Infrastruktur teknologi informasi saat ini. Infrastruktur teknologi informasi pada universitas saat ini dapat dibagi ke dalam dua kategori yaitu perangkat keras (hardware) dan perangkat lunak (software). Penjelasan mengenai tiap aktor dari arsitektur teknologi perusahaan saat ini dapat dilihat pada lampiran.

Dari keterkaitan arsitektur bisnis, arsitektur sistem informasi dan arsitektur teknologi, maka didapat sebuah blueprint yang bisa diajukan sebagai acuan untuk sebuah universitas dalam mengembangkan sistem informasi di lingkungannya dapat dilihat pada gambar 9 


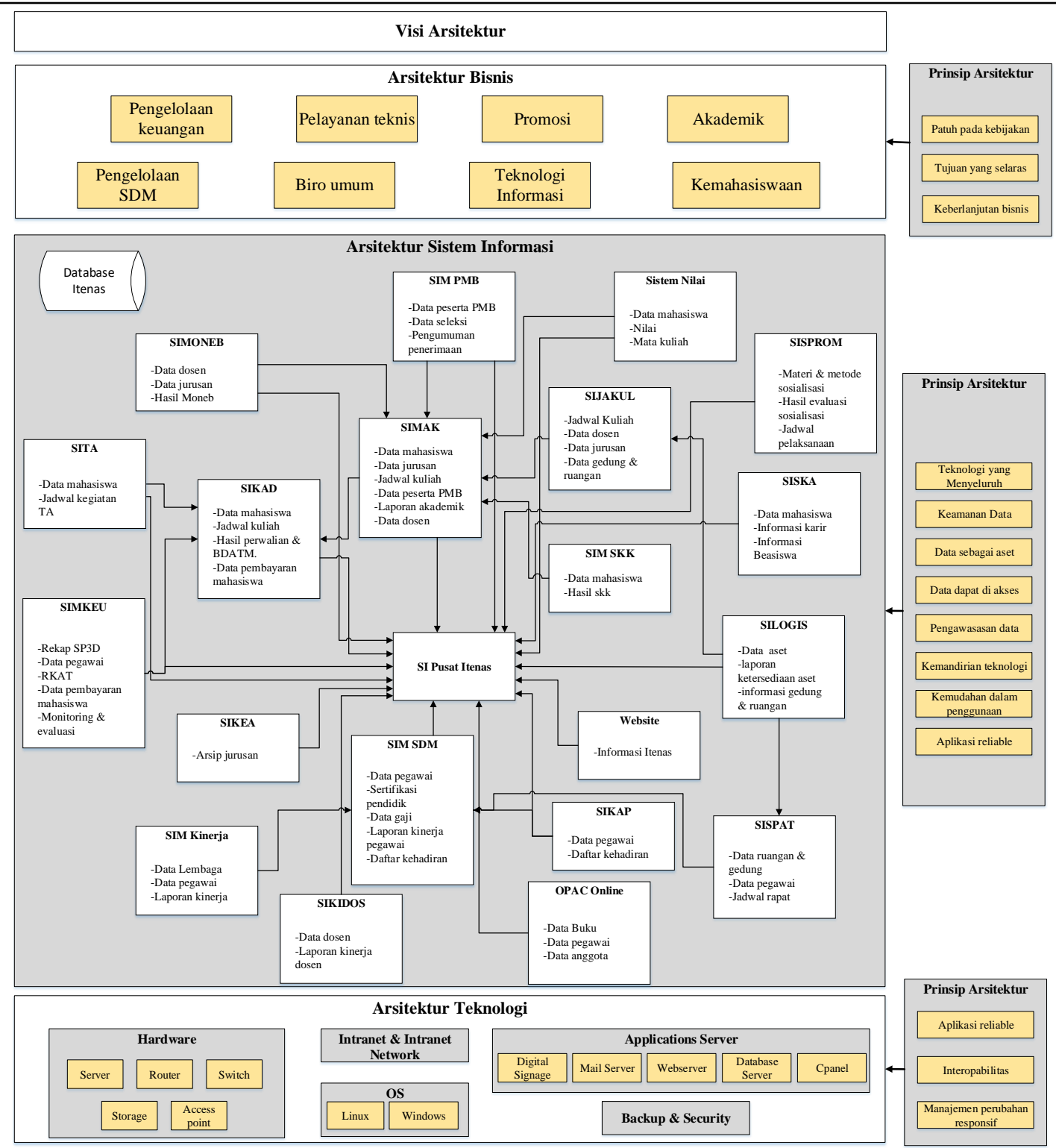

\section{Gambar 9 Arsitektur enterprise}

\section{IV.KESIMPULAN DAN SARAN}

Penerapan COBIT 4.1 untuk melakukan pengkuran kematangan TI di sebuah universitas dapat membantu merancang arsitektur enterprise, dengan menggunakan domain $\mathrm{PO} 2$ yang menghasilkan nilai kematangan 2,35 dan domain PO3 yang menghasilkan nilai kematangan 2,59. Hasil evaluasi penilaian yang memberikan kontribusi pada pendefinisian visi arsitektur dan perancangan target arsitektur teknologi. Hal-hal yang perlu diperhatikan pada perancangan arsitektur enterprise rencana strategis dan isu yang ada pada perusahaan tersebut. Perancangan arsitektur enterprise di salah satu universitas berhasil di lakukan dengan memetakan seluruh komponen TI hingga memberikan solusi dalam mengintegrasikannya sesuai dengan kebutuhan. Dengan ini diharapkan sebuah universitas dapat menerapkan arsitektur enterprise pada proses bisnisnya, agar seluruh teknologi informasinya dapat terdokumentasi dan saling terintegrasi satu sama lain

\section{REFERENSI}

Hevner, March, Park, \& Ram. (2004). Design Science in Information Systems Research. MIS Quarterly, 28(1), 75. https://doi.org/10.2307/25148625

IT Governance Institute. (2007). COBIT 4.1 Excerp. Retrieved from www.itgi.org

Mrdalj, S. (2016). A comparison of enterprise architecture frameworks, (December).

Sinyal, L., Itb, E., Itb, L. V., \& Bandung, J. G. (2016). 
INDONESIA Kuswardani Mutyarini, ST ., Dr . Ir . Jaka Sembiring, 102-107.

Standard, O. G., \& Group, T. O. (2011). TOGAF ${ }^{\circledR}$ Version 9.1.

Susanto, E. D. Y. (2018). Perancangan Model Arsitektur Enterprise Menggunakan Togaf Adm Guna Mendukung Sistem Informasi Akademik ( Studi Kasus Politeknik Indonusa Surakarta ).

Zachman, J. A. (1996). Enterprise Architecture: The Issue of the Century. 